\title{
Study of Inductively Coupled Plasma Etching of ZnS Materials
}

\author{
Jing Xing ${ }^{1}$, Yan $\mathrm{Xu}^{2}$ \\ ${ }^{1}$ School of Intelligence Science and Information Engineering \\ Xi'an Peihua University, Xi'an, China \\ 2ZTE Education Cooperation Center, Xi'an, China \\ acost123@163.com,437083790@qq.com
}

Keywords: Inductively coupled plasma; Zinc sulfide; Etching rate; Surface roughness

\begin{abstract}
In order to get the optimized process parameters for etching $\mathrm{ZnS}$ by inductively coupled plasma (ICP), a mixed gas of $\mathrm{CH}_{4}, \mathrm{H}_{2}$ and $\mathrm{Ar}$ is used for the etching. This paper studies the influence of ICP etching rate and surface roughness after etching of $\mathrm{ZnS}$ by changing the process parameters of $\mathrm{CH}_{4} / \mathrm{H}_{2} / \mathrm{Ar}$ gas mixing ratio, the total flow, bias power and $\mathrm{RF}$ power. The experimental result show that when $\mathrm{CH}_{4}: \mathrm{H}_{2}: \mathrm{Ar}=1: 7: 5$, the gas flow is $39 \mathrm{sccm}$, bias power is $80 \mathrm{~W}$, and $\mathrm{RF}$ power is $300 \mathrm{~W}$, the etching rate of $\mathrm{ZnS}$ is $18.5 \mathrm{~nm} / \mathrm{min}$ and the minimum surface roughness $R a$ is $6.3 \mathrm{~nm}$; the change of Ar content has a great influence on the etching rate and surface roughness.
\end{abstract}

\section{Introduction}

Zinc sulfide $(\mathrm{ZnS})$ is a wide bandgap II-VI compound semiconductor material with a band gap of $3.7 \mathrm{eV}$, which is mainly used in optoelectronic devices. Zinc sulfide material has extremely high light transmittance, and this material has extremely high anti-interference and mechanical reliability to the environmenta, can be used in the visible light, near infrared or far infrared light range in the open air environment [1]. Therefore, it has a broad application prospect to fabricate micro-optical devices on ZnS substrates.

For the fabrication of $\mathrm{ZnS}$ material optical elements, the etching process is mainly adopted. Since the chemical properties of $\mathrm{ZnS}$ are very stable at normal temperature, it is difficult to etch with wet method. Therefore, dry etching methods are mostly used at present. There are two types of etching gases commonly used for II-VI compound semiconductors. One is chlorine-containing gas (such as $\mathrm{Cl}_{2}, \mathrm{BCl}_{3}, \mathrm{CCl}_{4}, \mathrm{SiCl}_{4}$, or $\mathrm{CCl}_{3} \mathrm{~F}$, etc.) [2][3], the other is hydrocarbon gas. (such as $\mathrm{C}_{2} \mathrm{H}_{6} / \mathrm{H}_{2}$ or $\mathrm{CH}_{4} / \mathrm{H}_{2}$ ) [4][5]. The etching rate up to several hundred $\mathrm{nm} / \mathrm{min}$ with the first type of gas etching II-VI compound semiconductor material [6][7], The faster etching rate is not conducive to the manufacture of nano-scale fine structures, and the halogen elements are corrosive and toxic and have a certain impact on the environment. The second type of gas is neither toxic nor corrosive. The polymer produced during the reaction is deposited on the surface of the substrate and sidewalls, which will reduce the lateral etching rate and increasing the etching selectivity, however when using only hydrocarbon gas etching, the resulting reactants may not easily separate from the substrate surface, which will affect the etching process. At the same time, the chamber will be contaminated by the hydrocarbon polymer generated when the plasma of $\mathrm{CH}_{4} / \mathrm{H}_{2}$ reacts with the photoresist is deposited on the inner wall of the chamber, so the $\mathrm{O}_{2}$ cleaning chamber is often used. The addition of inert gases ( $\mathrm{He}, \mathrm{Ne}, \mathrm{Ar}, \mathrm{Kr}, \mathrm{Xe}$ ) to the etching gas can enhance ion bombardment and dilute the gas, and the inert gas does not participate in the chemical reaction process and does not affect the overall chemical composition. In the study of reactive ion etching experiment of $\mathrm{ZnO}$, Wante Lim et al [8] used the mixed gas of $\mathrm{CH}_{4} / \mathrm{H}_{2} / \mathrm{Xe}$, although the etching rate has increased, the physical sputtering effect is stronger, and the resulting etched surface is more damaged due to the large amount of Xe atoms. Some people in China have studied that when the reactive ion etching $\mathrm{GaN}$ is added with $\mathrm{He}$, the resulting surface is flatter than when $\mathrm{He}$ is not added [9]. Argon ions have significant effects in adjusting the passivation barrier and removing particulate deposits, and are relatively easy to obtain vertical corrosion effects. Therefore, when $\mathrm{ZnS}$ is etched using a hydrocarbon gas, an appropriate inert gas is introduced. 
Inductively coupled plasma (ICP) has the advantages of low damage, stable and controllable process, and high processing precision, which has become an ideal dry etching process. Therefore, this article uses inductively coupled plasma (ICP) technology to establish the process parameters for etching $\mathrm{ZnS}$ with the $\mathrm{CH}_{4} / \mathrm{H}_{2} / \mathrm{Ar}$ mixed gas. In order to meet the process requirements for etching various $\mathrm{ZnS}$ material devices and find the ideal etching process parameters, The main researches are the Ar content, total gas flow, and the influence of bias power and RF power on the etching rate and surface roughness of $\mathrm{ZnS}$.

\section{The Mechanism of $\mathrm{ZnS}$ Etching by Inductively Coupled Plasma}

Inductively coupled plasma etching is divided into physical etching and chemical etching. When $\mathrm{ZnS}$ is etched using a mixed gas of $\mathrm{CH}_{4} / \mathrm{H}_{2} / \mathrm{Ar}, \mathrm{H}_{2}$ and $\mathrm{CH}_{4}$ are used as chemical etching gases. In an inductively coupled magnetic field, they are ionized to generate hydrogen ions $\left(\mathrm{H}^{+}\right)$and methyl groups $\left(\mathrm{CH}_{3}{ }^{-}\right)$, which react with zinc and sulfur to generate different volatile products.

$$
\begin{aligned}
& \mathrm{Zn}_{2}{ }^{+}+\mathrm{CH}_{3}{ }^{-} \rightarrow \mathrm{Zn}\left(\mathrm{CH}_{3}\right)_{2} . \\
& \mathrm{S}_{2}{ }^{-}+2 \mathrm{H}^{+} \rightarrow \mathrm{H}_{2} \mathrm{~S} .
\end{aligned}
$$

$\mathrm{H}_{2}$ has no effective effect on $\mathrm{Zn}$, so the pure hydrogen etching $\mathrm{ZnS}$ is isotropic and the etching rate is very low. With the addition of methane, $\mathrm{Zn}\left(\mathrm{CH}_{3}\right)_{2}$, which is a readily desorbed $\mathrm{Zn}$ reaction product will be generated. The substrate surface of the etched will be smoother and the profile of the etched pattern will be sharper and have anisotropic characteristics. As a physical etching gas, Ar assists the sputtering in removing $\mathrm{Zn}\left(\mathrm{CH}_{3}\right)_{2}$ generated in the reaction, and plays a role of diluting the gas and stabilizing the plasma.

\section{Experiments and Methods}

The experiment uses the ICP-98A high-density plasma etching machine developed by the Institute of Microelectronics of the Chinese Academy of Sciences, which has the characteristics of high etching accuracy, good repeatability, and small damage. The device has two $13.56 \mathrm{MHz}$ RF power sources. The high-power (from 0 to $1500 \mathrm{~W}$ ) RF excitation power supplies generate high-density plasma by inductive coupling in the reaction chamber. The low-power (from 0 to $500 \mathrm{~W}$ ) bias power guides the vertical movement of ions to achieve the purpose of anisotropic and high-speed, low-damage etching. Compared with the conventional reactive ion etching equipment, the plasma density of this system is about 2 orders of magnitude higher, which can reach $10^{11}$ to $10^{12}$ per cubic centimeter. The background vacuum of the equipment is $3 \times 10^{-3} \mathrm{~Pa}$, and the wafer table is cooled by water at $20^{\circ} \mathrm{C}$.

In the experiment, a $\mathrm{ZnS}$ wafer with a radius of $5 \mathrm{~mm}$ and a thickness of $1 \mathrm{~mm}$ was used as a substrate, and a positive photoresist was used as a mask. We analyzed the effect of various process factors on the etch rate of $\mathrm{ZnS}$ and the surface roughness after etching, under the condition that the mass flow ratio between $\mathrm{CH}_{4}$ and $\mathrm{H}_{2}$ is maintained at 1:7 [2], by changing the gas flow rate (from 26 to $78 \mathrm{sccm}$ ), Ar content $\left(\mathrm{CH}_{4}: \mathrm{H}_{2}: \mathrm{Ar}=1: 7: \mathrm{a}\right.$, a is taken as 1, 3,5,7,9), ICP RF power (from 150 to $500 \mathrm{~W}$ ) and the bias power (form 0 to $150 \mathrm{~W}$ ). Finally, the process parameters of etching $\mathrm{ZnS}$ by $\mathrm{CH}_{4} / \mathrm{H}_{2} / \mathrm{Ar}$ were determined by combining the etching rate and the etching surface roughness. It is assumed that the standard etching conditions are: gas flow rate is $39 \mathrm{sccm}, \mathrm{CH}_{4}: \mathrm{H}_{2}: \mathrm{Ar}=1: 7: 5$, ICP radio frequency power is $300 \mathrm{~W}$, bias power is $80 \mathrm{~W}$. The surface roughness and etching depth of the sample after etching were measured using a Taylor Surf CCI2000 non-contact surface meter, and the measured etching depth was an average of a plurality of steps.

\section{Experimental Results and Analysis}

\subsection{Effect of Gas Flow Rate on Etch Rate and Roughness of ZnS}

The pressure in the reaction chamber of the ICP-98A high-density plasma etching machine cannot be adjusted manually, but changes with the total gas flow rate. Therefore, the change of the gas flow 
rate can be regarded as the result of the combined effect of the gas flow rate and the pressure. Under the standard conditions, the gas total flow rate was changed to $26 \mathrm{sccm}, 39 \mathrm{sccm}, 52 \mathrm{sccm}, 65 \mathrm{sccm}$ and $78 \mathrm{sccm}$ for the etching experiment. The relationship between total gas flow rate and the etching rate and surface roughness of $\mathrm{ZnS}$ is shown in figure1. It can be seen from figure1 that with the increase of the total gas flow rate, the etching rate of $\mathrm{ZnS}$ increased firstly and then decreased, and the surface roughness changed little when the gas flow rate was less than $50 \mathrm{sccm}$, and gradually increased when it exceeded $50 \mathrm{sccm}$.

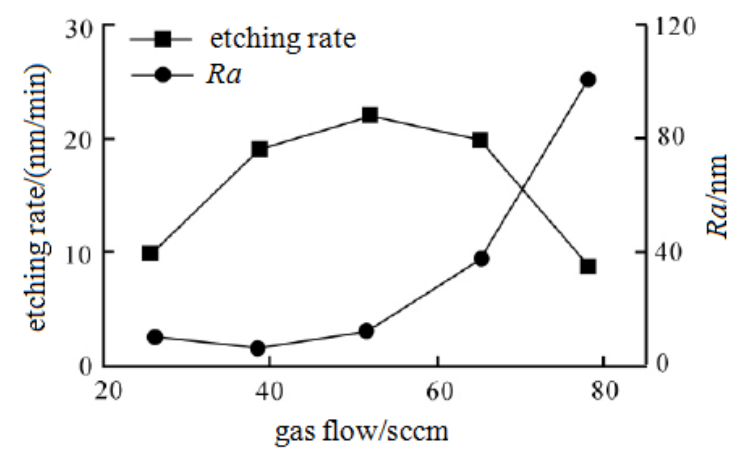

Figure 1. The relationship between the total flow and etch rates and surface roughness of $\mathrm{ZnS}$

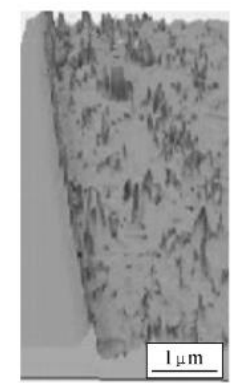

Figure 2. The etching topography of the gas flow at $72 \mathrm{sccm}$

When the total gas flow is less than $52 \mathrm{sccm}$, the pressure in the reaction chamber is lower than 1 Pa during operation. With the increase of the total flow, the plasma concentration increases in the reaction chamber, so the etching effects of physical and chemical are enhanced, the etching rate increases, and the surface roughness did not change much after etching. When the gas flow rate is greater than $52 \mathrm{sccm}$, although the total gas flow increases, the plasma concentration increases, but the pressure of the reaction chamber is relatively large, and the plasma compounding process is enhanced, resulting in the decreasing of the plasma concentration and the weakening of the bombardment effect between the high-energy ions and the $\mathrm{ZnS}$ surface, the reaction products cannot be discharged from the etched substrate surface in time and accumulated on the surface of the pattern and the sidewalls to prevent the etching of $\mathrm{ZnS}$, the etching rate decreases while the etching surface roughness increases. The etching topography of the gas flow at $72 \mathrm{sccm}$ is shown in figure 2 . It can be seen from the figure that there are deposits on the pattern surface and sidewalls, and the etched surface is very rough. The experiment shows that the surface roughness of $\mathrm{ZnS}$ is the smallest when the total gas flow is $39 \mathrm{sccm}$.

\subsection{Effect of Ar on Etch Rate and Roughness of $\mathrm{ZnS}$}

Under the standard conditions, we analyzed the effect of Ar content on the etching of $\mathrm{ZnS}$ by changing the ratio of $\mathrm{CH}_{4}, \mathrm{H}_{2}$ and $\mathrm{Ar}\left(\mathrm{CH}_{4}: \mathrm{H}_{2}: \mathrm{Ar}=1: 7: \mathrm{a}\right.$, a taken 1,3,5,7,9). The relationship between Ar content and the etching rate and the surface roughness of $\mathrm{ZnS}$ is shown in figure 3. It can be seen from the figure that when the Ar content is less than $38 \%$ of the total flow rate, the etching rate increases and the surface roughness decreases with the increase of Ar content. When the content is more than $38 \%$, the etching rate first decreases slowly and then increases and the surface roughness increases with the increase of Ar content. 


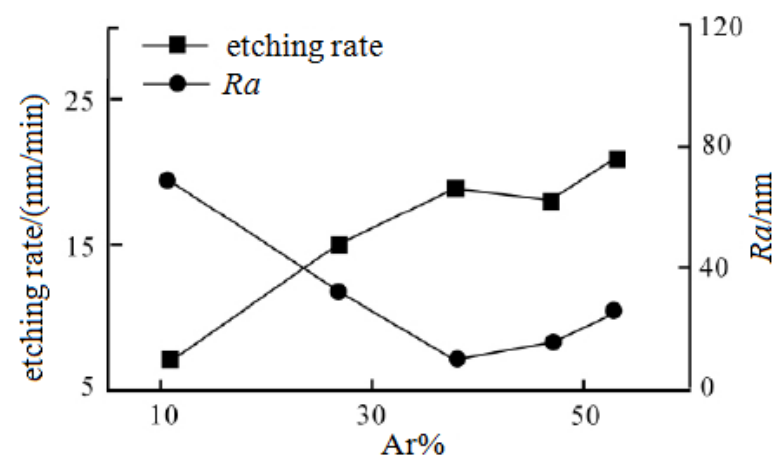

Figure 3. The relationship between Ar content and etch rates and surface roughness of $\mathrm{ZnS}$

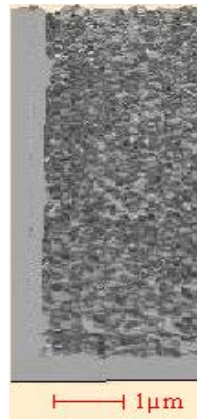

Figure 4. Etching morphology of Ar content 11\%

When the Ar content is low, physical etching is weak, mainly based on chemical etching. The reaction products cannot be completely sputtered and adsorbed on the surface of the substrate, which inhibits the etching process. At the same time, too much $\mathrm{CH} 4$ content will cause polymer deposition [10]. Figure 4 shows the etching topography when the Ar content is $11 \%$. It can be seen from the figure 4 that there is a black material deposition on the etched surface. This is can be explained by the reaction mechanism of $\mathrm{ZnS}$. Because the $\mathrm{H}_{2} \mathrm{~S}$ generated in the reaction is easily volatilized from the surface of $\mathrm{ZnS}$, and the boiling point of $\mathrm{Zn}\left(\mathrm{CH}_{3}\right)_{2}$ is $46^{\circ} \mathrm{C}$, it needs to be sputtered form the surface by physical bombardment. The presence of $\mathrm{Zn}$ element prevents the etching, so the etching rate is low and the surface is rough. With the increase of Ar content, the physical etching effect of $\mathrm{Ar}^{+}$increases gradually, and $\mathrm{Zn}\left(\mathrm{CH}_{3}\right)_{2}$ is sputtered out of the substrate surface in time, so the etching rate of $\mathrm{ZnS}$ gradually increases and the surface roughness decreases. When the Ar content is $38 \%$, physical etching and chemical etching reach a certain balance, the etching rate relatively increases, and the roughness decrease.

Because the influence of chemical etching is greater than the effect of physical etching during inductively coupled plasma etching of $\mathrm{ZnS}$, when the $\mathrm{Ar}$ content is between $38 \%$ and $47 \%$, the amount of active required for the reaction is slightly lower than that at equilibrium, and physical bombardment is not strong enough, so the etching rate is slightly reduced. When the Ar content is greater than $50 \%$ of the flow rate, although the reactive ion of the reaction is reduced, the physical etching is enhanced, and the total etching rate of is increased. Because the physical etching has an isotropic effect and is not conducive to the fabrication of the $\mathrm{ZnS}$ device profile, so we chose a process parameter of $\mathrm{CH}_{4}: \mathrm{H}_{2}: \mathrm{Ar}=1: 7: 5$.

\subsection{Effect of Bias Power on Etch Rate and Roughness of ZnS}

The relationship between bias power and the etching rate and surface roughness of $\mathrm{ZnS}$ is shown in figure 5. Under the standard conditions, we changed the bias power to $0 \mathrm{~W}, 50 \mathrm{~W}, 80 \mathrm{~W}, 100 \mathrm{~W}$ and $300 \mathrm{~W}$ for the etching experiment. It can be seen from figure 5, as the bias power increases, the etching rate monotonously increases, and the surface roughness decreases first and then increases. 


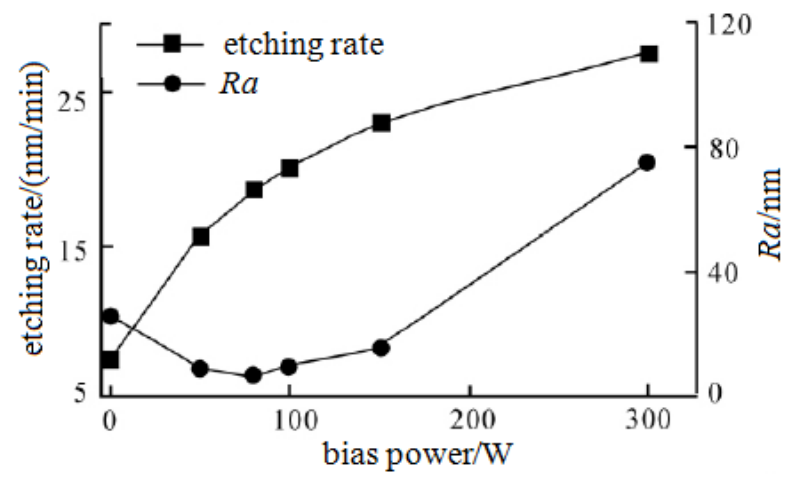

Figure 5. The relationship between RF power and etch rate and surface roughness of $\mathrm{ZnS}$

The magnitude of the bias power determines the self-bias of the substrate in the reaction chamber, which determines the energy of the active radical when it reaches the surface of the substrate, and the plasma can be to vertically etch the substrate. When the bias power is small, the energy of reactive groups $\mathrm{CH}_{3}{ }^{-}$and $\mathrm{H}^{+}$in the plasma reaches the surface of the substrate is small, the chemical reaction is not performed sufficiently, and the etching product $\mathrm{Zn}\left(\mathrm{CH}_{3}\right)_{2}$ cannot be sputtered out of the sample surface effectively. Therefore, the etching rate is small, and the surface roughness after etching is large. With the increase of the bias power, the energy of the active groups $\mathrm{CH}_{3}{ }^{-}$and $\mathrm{H}^{+}$that reaches the surface of the substrate and the energy of the impact of the chemical reaction process also increases, which accelerates the chemical reaction of the etched surface and the desorption of the less volatile products. The etching rate increases and the etched surface roughness decreases. When the bias power is about $80 \mathrm{~W}$, the surface roughness after etching is small.

\subsection{Effect of Bias Power on Etch Rate and Roughness of ZnS}

The relationship between RF power and etch rate and etched surface roughness is shown in figure 6. Under the standard conditions, we changed the RF power from $150 \mathrm{~W}$ to $500 \mathrm{~W}$ for the etching experiment. It can be seen from figure 6 that as the RF power increases, the etching rate of $\mathrm{ZnS}$ monotonically increases, and the etched surface roughness first decreases and then increases.

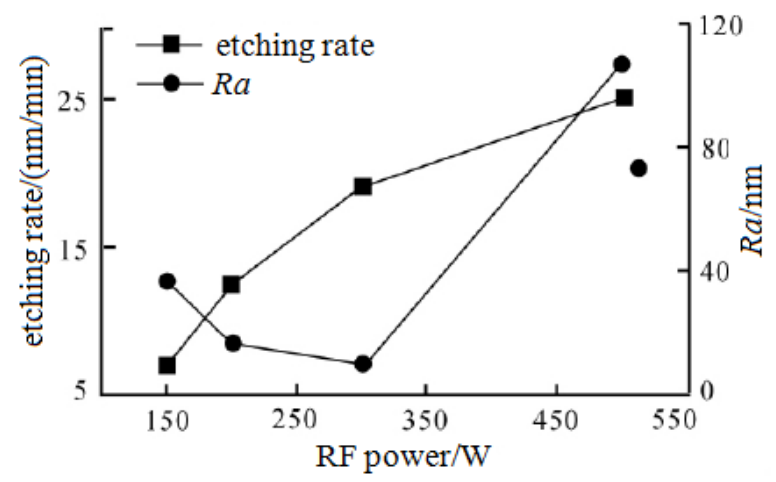

Figure 6 The relationship between RF power and etch rate and surface roughness of $\mathrm{ZnS}$

The RF power mainly determines the plasma concentration in the reaction chamber. When the RF power is increased, on the one hand the plasma concentration is higher; on the other hand, the energy provided to the free electrons in the plasma is greater. With the increase of RF power, more free radicals and ions are generated by high-energy free electrons colliding with the etching gas molecules. The increase of $\mathrm{CH}_{3}{ }^{-}$and $\mathrm{H}^{+}$enhances the mechanism of chemical action in plasma etching. The physical and chemical etching effects are enhanced, so the etching rate increases. When the RF power is small, the plasma concentration and energy are small, and the surface roughness is large. However, the $\mathrm{RF}$ power is not as great as possible, when the RF power is too high, the reaction products $\mathrm{Zn}\left(\mathrm{CH}_{3}\right)_{2}$ and $\mathrm{H}_{2} \mathrm{~S}$ are accelerated and they cannot be removed by the vacuum system in time, so the secondary deposition occurs and the sample surface and the vacuum chamber are contaminated. The etched surface roughness also increases. When RF power is $300 \mathrm{~W}$, the etched surface roughness is minimal. 


\section{Conclusions}

(1) Through the comparison of the etching rate and the surface roughness of $\mathrm{ZnS}$, the most suitable process parameters for etching $\mathrm{ZnS}$ by inductively coupled plasma reaction were established: the total gas flow was $39 \mathrm{sccm}, \mathrm{CH}_{4}: \mathrm{H}_{2}: \mathrm{Ar}=1: 7: 5$, the $\mathrm{RF}$ power was $300 \mathrm{~W}$ and the bias power was $80 \mathrm{~W}$. Under the above conditions, the etching rate was $18.5 \mathrm{~nm} / \mathrm{min}$. Among them, the Ar content determined the physical and chemical etching degree of $\mathrm{ZnS}$ by inductively coupled plasma etching, which is the main factor affecting $\mathrm{ZnS}$ etching.

(2) Under the above process parameters, we fabricated the components of $\mathrm{ZnS}$ material. The relationship between the surface roughness after etching and the process parameters was as follows: With the increase of the total gas flow and the bias power, the surface roughness gradually increases; with the increase of Ar content and RF power increases the surface roughness decreased firstly and then increased. The minimum surface roughness $R a$ after etching is $6.3 \mathrm{~nm}$.

(3) Since the $\mathrm{CH}_{4} / \mathrm{H}_{2}$ plasma reacts with the photoresist and the generated hydrocarbon polymer is deposited on the surface and sidewalls of the $\mathrm{ZnS}$ substrate pattern, the surface roughness after etching is larger than that using the chlorine-based gas. In order to eliminate the influence of hydrocarbon polymers on the surface roughness, other devices that alternately recycle the $\mathrm{CH}_{4} / \mathrm{H}_{2} / \mathrm{Ar}$ etching gas and $\mathrm{O}_{2}$ during operation can be considered.

\section{References}

[1] WANG Han, XU Guo-yue, WENG Lv-qian. 2004. The Infrared Emissivity Research of Micrometer Sulfide Semiconductor, Journal of Functional Materials, 35(Suppl):283-285.

[2] REN Yuan, LIU Xiaoyuan,LIU Jincheng. 2016.Study of inductively coupled plasma etching of GaN. Materials Research and Application, 10(3):214-218.

[3] Jong-Chang Woo, Tae-Kyung Ha, Chen Li. 2011. Dry Etching Characteristics of Zinc Oxide Thin Films in $\mathrm{Cl}_{2}$-Based Plasma. Transactions on electrical and electronic materials. 12(2):60-63.

[4] K.Ip, M.E.Overgerg, R.G.Wilson. 2003. ICP Dry Etching of ZnO and Effects of Hydrogen, Solid-State Electronics, 47:2289-2294.

[5] LI Zhen, Hu Xiao-yan, SHI Chun-wei. 2008. A Study of MCT Contact Hole Etching by ICP Process, Laser and Infrared, 12(38):1211.

[6] S Bouchoule, L Vallier, G Patriacrche. 2012. Effect of $\mathrm{Cl}_{2-}$ and $\mathrm{HBr}$-based inductively coupled plasma etching on InP surface composition analyzed using in situ x-ray photoelectron spectroscopy. Journal of Vacuum Science and Technology,30(3):031301-11.

[7] J.W.Bae, C.H.Jeong, J.T.Liml. 2007. Anisotropic Etching of InP and InGaAs by Using an Inductively Coupled Plasma in $\mathrm{Cl}_{2} / \mathrm{N}_{2}$ and $\mathrm{Cl}_{2} / \mathrm{Ar}$ Mixtures at Low Bias Power, Journal of the Korean Physical Society, 50(4):1130-1135.

[8] Wantae Lim, Lars Voss, Rohit Khanna. 2006. Dry etching of bulk single-crystal ZnO in $\mathrm{CH}_{4} / \mathrm{H}_{2}$-based plasma chemistries, Applied Surface Science, 25(3):889-894.

[9] LIU Bei-ping, LI Xiao-liang, ZHU Hai-bo. 2006. $\mathrm{Cl}_{2}$-based Dry Etching of GaN Using Inductively Coupled Plasma, Journal of Semiconductors, 27(7):1135-1338.

[10] Atsushi Okita, Yoshiyuki Suda, Akinori Oda. 2007. Effects of hydrogen on carbon nanotube formation in $\mathrm{CH}_{4} / \mathrm{H}_{2}$ plasmas, Carbon, 45(3):1518-1526. 